\title{
Designing Public Spaces for Democratic Stories
}

\author{
Mike Ananny, Carol Strohecker \\ Everyday Learning, Media Lab Europe \\ Sugar House Lane, Bellevue, Dublin 8, Ireland \\ \{ananny, stro\}@medialabeurope.org
}

\begin{abstract}
We argue that civic discourse can also be public storytelling and propose three reasons to consider this relationship: stories' relational nature - their ability to represent uniquely human perspectives and emotions - may ameliorate aspects of citizens' disinterest in civic life; the ability of stories to represent both individual perspectives and cultural norms may offer a form of public opinion that is relevant on both personal and collective scales; and the inherent transparency of familiar narrative forms may offer new ways to explicate unfamiliar aspects civic discourse. We propose a relationship between civic discourse and public storytelling and review one system called TexTales in relation to a developing model of "democratic stories."
\end{abstract}

\section{Author Keywords}

Public opinion, democratic stories, participatory design, community installation.

\section{ACM Classification Keywords}

H.5.1 Multimedia Information Systems; H.5.2 User Interfaces; H.5.3 Group and Organization Interfaces

\section{INTRODUCTION}

We explore a connection between story authorship and civic discourse, using a review of a system we built, called "TexTales", as a way of developing this thinking. The system was originally built to investigate new forms and forums for shaping and reflecting the development of public opinion. Here, our aim is even more experimental: to review this system in light of narrative construction principles and to posit a "democratic story" that may serve as a bridge between forms of narrative and representations of public opinion.

To construct a story is to relate perspectives. Good stories do not have to resolve conflict or force agreement but they do have to represent viewpoints, explicate differences and create coherent representations. Polanyi [9] emphasizes the structural nature of stories, arguing that conventional

Ananny, M., and Strohecker, C. 2004. Designing public spaces for democratic stories. Proceedings of the First ACM Workshop on Story Representation, Mechanism \& Context, Multimedia, 47-50.

Permission to make digital or hard copies of all or part of this work for personal or classroom use is granted without fee provided that copies are not made or distributed for profit or commercial advantage and that copies bear this notice and the full citation on the first page. To copy otherwise, or republish or post on servers or to redistribute to lists, requires prior specific permission and/or a fee.

SRMC'04, October 15, 2004, New York, New York, USA. Copvright 2004 ACM 1-58113-931-4 /04/0010...\$5.00. narratives (with coherent changes in character, place, time or event) help listeners understand individual perspectives and that tellers purposefully use story strategies to convey specific meanings and progressions of ideas. Linde [6] describes a particular kind of narrative, a "life story", which is not a general view of the world but is instead a socially situated, individual story that is told and retold over the course of a lifetime. These two senses of story - Polanyi's structured forms and Linde's personal developments - are relevant to our own proposal that civic discourse can also be storytelling if we have ways to support the democratic construction of personal and collective narratives ${ }^{1}$.

\section{STORY AND CIVIC DISCOURSE}

Considering stories in relation to civic discourse and public deliberation challenges both Polanyi's functional structures and Linde's individual expressions. Noveck [7] states that public deliberation is "a special form of speech structured according to democratic principles and designed to transform private prejudice into considered public opinion and produce more legitimate solutions." Noveck claims that such discourse must be: accessible, uncensored, created by participants, accountable, attributed not anonymous, transparent, equal, pluralistic, inclusive, informed, public and facilitated. If narratives are to be democratic discourse (not just discourse in a public space) there are additional burdens on the ways in which democratic stories must be constructed and represented.

Why consider stories in relation to civic discourse? We think there are three reasons to investigate such a relationship: stories' relational nature - their ability to represent perspectives and emotions - may ameliorate aspects of citizens' disinterest in civic life; stories' ability to represent both individual perspectives and cultural norms may offer a form of public opinion that is relevant on both personal and collective scales; and the inherent transparency of familiar narrative forms may offer new ways to explicate unfamiliar aspects civic discourse. People might think differently about public issues if they were represented in ways that were personal, broadly relevant and self-constructed.

\footnotetext{
${ }^{1}$ See [1] for a further discussion of this idea of shifting between personal and public scales of authorship.
} 
On this first point of leveraging stories' relational form, there is a concept in public opinion research called "rational ignorance" [3] that aims to explain people's perceived apathy for democratic processes. Since democracies are based on the premise of equality in the primary means of citizen participation - voting: one person, one vote "rational ignorance" says that there may be a disincentive for individuals to learn about public issues. If people only have one vote, why expend time and energy learning about current affairs if their contributions are only one in many? Research on how people respond to opinion polls confirms this phenomenon, showing that people often have unstable "non-attitudes" [2] when they respond to surveys and answers on questionnaires bear little resemblance to their thinking in more deliberative settings. In his Deliberative Polls, Fishkin [4] contrasts "debilitated but actual opinion" (as expressed in representative snap-shot opinion polls) against "deliberative but counterfactual opinion" (as developed through longer-term dialogue). Citizen-created stories may offer ways for individuals to relate to each other as authors and audiences (not only as citizens and constituents) and to understand each others' public opinions as expressive communication (not only poll responses).

Related to the ideas of rational ignorance and civic apathy is the notion that traditional treatments of public opinion favour equitable counting of votes over rigorous treatment of ideas. Peters [8] argues that there is a danger in our reliance on the principle of one person, one vote: our desire to count all voters equally may make us mistakenly equate the ideas behind the votes. He reminds us that a vote is a marker, a container and a starting point for rich data that we rarely unpack in ways other than focus groups. Simple representations may inadvertently collapse rich ideas.

If stories offer ways to relate to and represent civic discourse, their familiar forms may also offer discernable and transparent representations of public discussion. In her arguments for inclusive political communication, Young says that narratives are ways that "people whose experiences and beliefs differ so much that they do not share enough premises to engage in fruitful debate can nevertheless reach dialogical understanding." [11] Considering stories as operational forms with familiar structures may help citizens develop ideas in ways that purely quantitative representations may not afford. We aim to create representations of civic discourse whose scaling is both democratically robust and deeply personal.

\section{DEMOCRATIC STORIES}

We define democratic stories as stories whose construction and expression constitute a representation of certain aspects of public opinion. They are:

- garnered and represented equitably with no particular segment dominating the story representation;

- constructed transparently and publicly, with any kind of filtering or editing being transparent and public;
- represented in multiple media that are personal, evocative and that convey emotional expression;

- developed in open and dynamic ways and not forcing convergence on any particular viewpoint or conclusion.

Here we describe our system TexTales, built to experiment with civic discourse forms, and review it with respect to these features of democratic stories.

\section{TEXTALES}

TexTales is a large, city-scale, interactive public installation that displays a 3-by-3 grid of image-text combinations. People create image captions by sending an SMS text message from their mobile phones to a chosen picture.

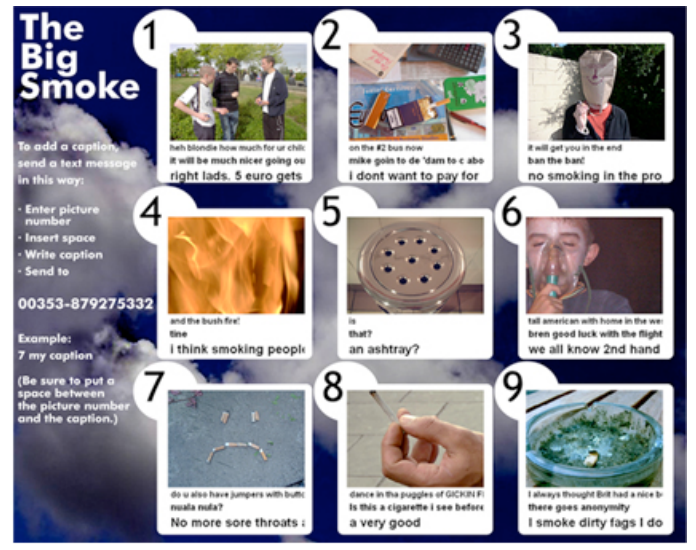

Figure 1: A TexTales display. People create captions by sending SMS texts with their mobile phones. Approximately 15 seconds later the interface displays the caption. The three most recent captions are displayed for each image.

In the last year we conducted installations in four different locations, working with four different groups of people to design installation content for four different public spaces: a low-income apartment complex in Dublin, Ireland; a public square in the city centre of Dublin, Ireland; a train station in Amsterdam, The Netherlands; and a community centre in Kilkeel, Northern Ireland. Each installation lasted approximately four hours for two consecutive evenings.

In preparation for each installation we worked with a group of local people to take pictures interpreting a particular topic: urban regeneration; a workplace smoking ban; teen attitudes towards smoking; and young people's opinions on sectarian conflict. Participants first met to discuss their topic and what pictures might best spur conversation; they then took pictures and reassembled to critique and edit each others' images, planning any further shooting needed to illustrate their issue. The critiques offered a way for us, as a group, to discuss biases of photographers and their images and to reveal different styles of creating image-text combinations. Some participants wanted to communicate a particular stance and sought specific photos to present their perspective. Others imagined captions that might engage the public and used these texts and the imagined discussion as guides for their shooting. Others took pictures in a less 
directed manner, using their cameras to chronicle activities that were later related to the installation's overall theme.

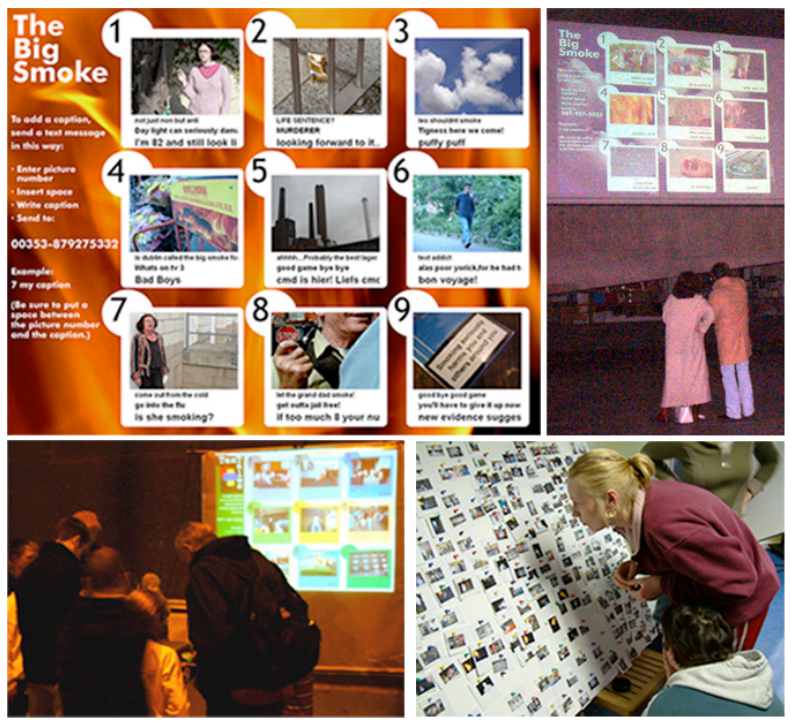

Figure 2: Top left: TexTales interface. Top right: two people texting to a Dublin installation. Bottom left: a group of texters at a Dublin installation. Bottom right: A group of participant designers selecting from among their own images the pictures for a Dublin TexTales installation.

Each process culminated in a public installation in which passers-by were invited to view the installation and add captions; more than 400 SMS text captions were sent across all four installations. Then, with the original designerparticipants, we analysed these texts and their relationships to the images, extracting patterns in the publics' attitudes toward each installation and its topic.

\section{TEXTALES AND DEMOCRATIC STORIES}

The first aspect of TexTales to review is its conversational nature. As each group designed their particular installation, we asked them not just to take pictures or to write captions but instead to create "conversation starters". Our aim was to see each image-text combination as a starting point for the larger public conversations that would take place during the installations. The challenge was to create combinations that constrained the installation's topic but that were still broad enough to evoke reactions from - and invite participation by - a general public audience. We could not know exactly who might participate or how they might perceive each image-text combination or whether the broad topic would be of interest. The preparation process consisted of imagining audiences, anticipating interpretations and designing "intermodal short forms" [10] to spur discussion. As passers-by entered each installation, they often began by viewing the current state of the installation, engaging their fellow on-lookers and texters and then adding comments or questions that emerged from these conversations. The reflections "in the interface" were distillations of the conversations "around the interface," which in turn reflected changes in the displays.
In addition to these conversational distillations, TexTales encompasses three other "short forms": the contact-sheet, photo-essay style juxtaposition of thumbnail images are best read when images have one or two strong visual elements; the use of the SMS genre as the means of captioning (e.g. "C u 18r" for "see you later", ); and the limitation or benefit of viewing only three caption lines under each image. We think that the compressions and distillations we observed citizens making with and around TexTales installations are in the spirit of Peters' [8] observation that "democracy has always depended on intellectual devices of abbreviation ... summation is one of its chief operations."

The second aspect of TexTales to review is its ability to garner and represent perspectives in an equitable manner. One way TexTales addresses the need for pluralism is to use both image and text to represent and elicit personal expressions. Traditional measures of public opinion like polls and surveys rely on people's reactions to preformed categories and questions, not on their ability to express ideas. TexTales is a step toward systems that support people in whatever medium they feel best supports their style of communication and the current issue. Another pluralistic aspect of TexTales is its use of the mobile phone as the main input device. We used the mobile phone because of its ubiquity $^{3}$ and, in Europe, the popularity of SMS text messaging. Although not everyone has a mobile phone or is experienced with texting, we preferred it over a specially designed handheld device or a kiosk because mobile phones allow for a kind of nomadic authoring to which most people are accustomed. This familiarity, however, exposed an interesting tension: since people usually use mobile phones to send personal notes, not to broadcast public messages, we were able to observe how people use familiar devices in new settings.

The third aspect of TexTales to review is the whether its expressions are created transparently and publicly. The installations developed through several phases, some more or less transparent and public than others. The initial framing of each installation and the creation, selection and arrangement of images and starter captions occurred among a relatively small group of participant-designers from each community in which TexTales was to appear. This process took between 3 weeks and 4 months, was highly iterative and involved at least a dozen members of the community, but it did not involve the general public. The next phase was advertising the installations in a variety of media (posters, radio, newspapers) and situating them in high-

\footnotetext{
2 See [5] for a discussion of the SMS texting and teenagers' appropriation of it for social communication.

${ }^{3}$ The 2002 World Almanac and Book of Facts states the mobile phone penetration rates for general populations in the three countries we conducted TexTales installations (Ireland, The Netherlands and the UK) as, respectively: $76 \%, 72 \%$ and $84 \%$.
} 
traffic public venues. All text messages received were displayed within approximately 15 seconds of receipt with no intervening censorship - with one exception. For the Northern Ireland installation on young people's attitudes toward sectarianism, our partnership with the BBC and our concerns about safety necessitated a form of censorship: a second computer was added to hold incoming text messages in a one-minute buffer during which time - and in clear view of the assembled crowd - the participant-designers, one of us (Ananny) and a BBC producer reviewed captions against an agreed upon set of guidelines. Thus, although this installation required censorship, our compromise was to make the mechanisms of censorship as public as possible. (Our fears proved unrealized: by the evening's end we had not blocked a single caption.) We failed to anticipate another method of public editing that a young Irish participant demonstrated to us. Since TexTales displays only the three most recent captions for any image, if someone finds a caption unacceptable, she can send three captions to that image in rapid succession, "bumping out" the offending caption and taking the conversational floor.

The fourth aspect of TexTales to review is its ability to support open-ended conversation that does not force convergence, conclusion or agreement. Except for the kind of public editing described above, TexTales installations are not moderated in any way: they take the directions of the participants and only end when the installations end.

\section{CONCLUSIONS}

TexTales stories do not fulfill Polayni's requirements for stories. They do not have well-formed narrative arcs with clear changes in character, place, time or event, nor do they converge to any kind of ending. Instead, they are heavily influenced by the compositional capabilities of mobile phones, the rendering features of the TexTales display and the public-private tensions associated with publishing with mobile phones. TexTales stories seem to be closer to Linde's "Life Stories": they are developmental in nature and are only coherent when considered over time, in relation to multiple media, a variety of authors, and with respect to distilled verbal conversations and compressed textual expressions.

In considering this work in relation to public opinion research it is worth revisiting Fishkin's distinction between "debilitated but actual" opinion versus "deliberated but counterfactual" opinion. TexTales installations are not representative in any rhetorical or demographic way: we likely missed many perspectives of many people. Rather, they should be thought of as differently elicited starting points for on-going public discourse and experiments with different forms public conversations might take. Further work is required to determine how TexTales might support ongoing dialogue. Longer term installations are required, as well as experimentation with different media and interaction techniques. Replacing the static images with short movie clips may allow for different perspectives within a single TexTales frame; letting passers-by contribute images in real-time using their mobile phones and from different locations may help us better understand how people collaboratively relate images and text in realtime and how place-based narratives may evolve. Finally, a more sophisticated discourse system that, for example, dynamically foregrounded and backgrounded images and captions may offer clues to how people think about managing democratic conversations.

TexTales stories are not traditional stories, but perhaps this is because they carry the added burden of representing particular aspects of public opinion. Each installation was, however, a democratic story: authored and revised publicly by multiple voices and over time in personal and public venues - and with no exact end.

\section{ACKNOWLEDGMENTS}

Thanks to Media Lab Europe's Everyday Learning group; our collaborators from Fatima Mansions, The Ark, BBC Northern Ireland, Young@Art, the Bridge Youth Project, the Amsterdam Computer Clubhouse; and everyone who shared their images \& txt msgs ;-)

\section{REFERENCES}

1. Ananny, M., Strohecker, C. \& K. Biddick (In Press). Shifting Scales on Common Ground: Developing Personal Expressions and Public Opinions. International Journal of Continuing Engineering Education and Life-Long Learning.

2. Converse, P.E. (1970). Attitudes and Non-Attitudes: Continuation of a Dialogue. In Tufte, E.R. (Ed.) The Quantitative Analysis of Social Problems. Addison-Wesley.

3. Downs, A. An Economic Theory of Democracy. New York, NY: Harper and Row, 1956.

4. Fishkin, J. (2000). Virtual Democratic Possibilities: Prospects for Internet Democracy. Paper presented at conference Internet, Democracy and Public Goods. Belo Horizonte, Brazil, November 6-10, 2000.

5. Grinter, R.E. \& M. Eldridge. (2003). Wan2tlk?: Everyday Text Messaging. Proceedings of CHI 2003, Ft. Lauderdale, Florida. April 5-10, 2003, pp. 441-448.

6. Linde, C., Life Stories. New York, NY: Oxford University Press, 1993.

7. Noveck, B.S. Unchat: Democratic Solution for a Wired World. In Shane, P. (Ed.) "The Prospects for Electronic Democracy." Routledge, 2004.

8. Peters, J.D. (2001). "The Only Proper Scale of Representation": The Politics of Statistics and Stories. Political Communication. 18:433-449.

9. Polanyi, L., Telling the American story. Cambridge, MA: MIT Press, 1989.

10. Strohecker, C. \& M. Ananny (2003). Constructing Intermodal Literacies. Proceedings of Technology Enhanced Learning. Milan, Italy. November 20-21, 2003.

11.Young, I.M. Inclusion and Democracy. Chapter 2: "Inclusive Political Communication") New York, NY: Oxford University Press, 2000. 